\title{
Микроструктурированные волоконные световоды с наведенной киральностью
}

\author{
А.В. Бурдин ${ }^{1,2,3}$, К.В. Дукельский ${ }^{1}$, В.В. Демидов ${ }^{1, *}$, Е.В. Тер-Нерсесянц \\ ${ }^{1}$ АО "НПО ГОИ им. С.И. Вавилова" \\ ${ }^{2}$ Поволжский государственный университет телекоммуникаџий и информатики \\ ${ }^{3}$ ООО "ОптоФайбер Лаб" \\ *E-mail: demidov@goi.ru
}

DOI: 10.31868/RFL2020.162-163

В работе представлены результаты исследования характеристик изготовленных пилотных образцов микроструктурированных оптических волокон (МС OB) двух типов геометрии с наведенной в процессе вытяжки киральностью, составляющей 10 и 66 оборотов/метр, соответственно.

К первой группе относятся МС ОВ гексагональной геометрии сердцевины, соответствующим образом сформированная 2D-периодическая волоконная структура которой обеспечивала имитацию волоконного световода с кольцевой сердцевиной. На рис. 1 представлена фотография торца изготовленного МС ОВ группы \#01, характеризуемого следующими параметрами: число порядков отверстий круглого сечения - 4; период (расстояние между отверстиями) - 10.35 мкм; отношение диаметра отверстия к периоду - 0.6; внешний диаметр - 125 мкм. Приведенные характеристики использовались в качестве исходных данных к расчету МС ОВ на оптической несущей $\lambda=1550$ нм.

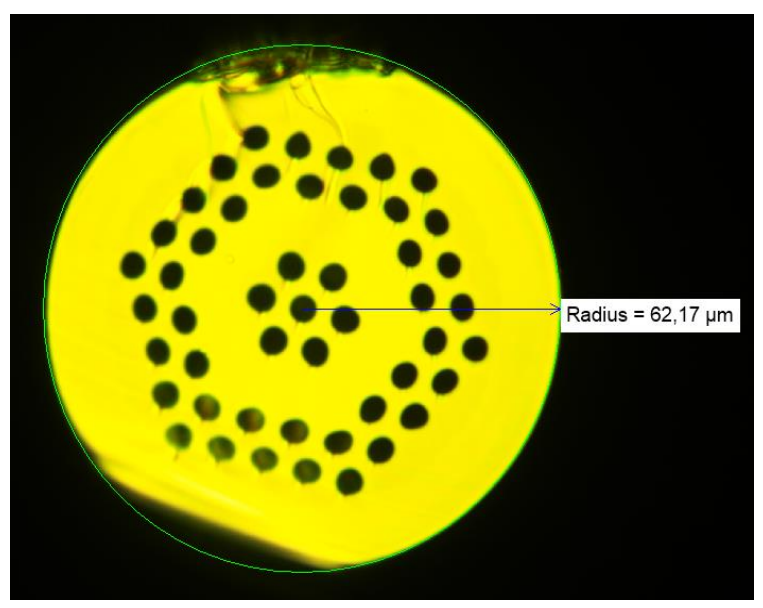

Рис. 1. Фотография торца МС ОВ группы \#01 гексагональной геометрии с кольцевым радиальным распределением полей мод

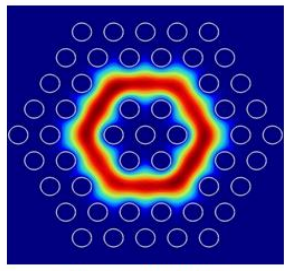

$L P_{01} ; n_{e f f}=1.442975$

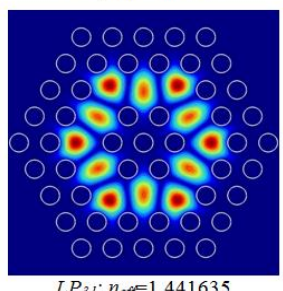

$L P_{31} ; n_{\text {eff }}=1.441635$

Рис. 2. Радиальное распределение полей основной и некоторых высших мод МС ОВ группы \#01( $\lambda=1550$ нм $)$

Некоторые полученные в результате проведенного расчета радиальные распределения полей мод представлены на рис. 2. Всего условию отсечки на указанной длине волны удовлетворяет 12 мод. На следующем этапе было проведено сканирование распределения пучка оптического излучения, возбуждаемого когерентным источником оптического излучения на длине волны 1550 нм с выхода пилотных образцов описанных МС ОВ в дальнем поле. В качестве примера на рис. 3 представлены результаты измерений, проведенные для МС ОВ группы \#01, вытянутых с периодом наведенной скрутки 66 оборотов/метр.

Вторую группу составили маломодовые МС ОВ с несимметричной гексагональной геометрией, предполагающей смещение сердцевины относительно цен- 
тральной оси симметрии ОВ при следующих параметрах: число порядков отверстий -4 ; расстояние между соседними отверстиями - 14.85 мкм; диаметр отверстия -7.15 мкм; отношение диаметра отверстия к шагу структуры - 0.65; диаметр сердцевины - 14.85 мкм; внешний диаметр - 125 мкм.
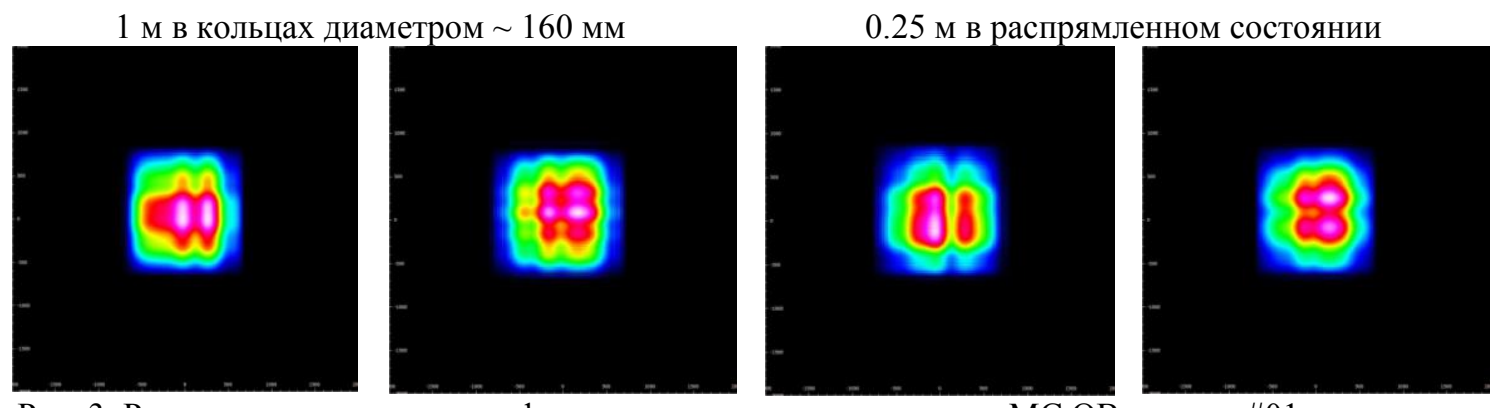

Рис. 3. Результаты измерения профиля лазерного пучка на выходе МС ОВ группы \#01 с периодом наведенной скрутки 66 оборотов/метр

Соответственно, на рис. 4 представлена фотография торца изготовленного МС ОВ группы \#02, на рис. 5 - расчетные радиальные распределения полей мод, на рис. 6 - результаты измерения профиля пучка оптического излучения лазера (длина волны $\lambda=1550$ нм) с выхода пилотных образцов описанных МС ОВ группы \#02 с периодом наведенной скрутки 66 оборотов / метр в дальнем поле.

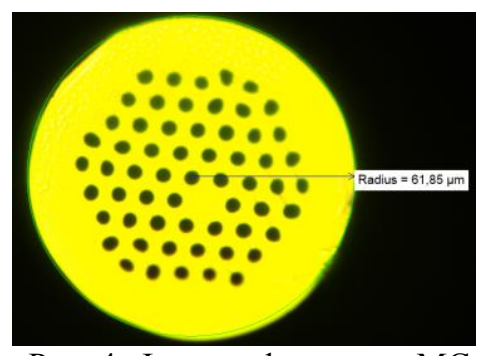

Рис. 4. Фотография торца МС ОВ группы \#02

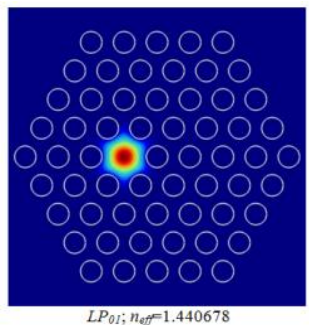

Рис. 5. Радиальное распределение полей некоторых мод МС ОВ группы \#02
1 м в кольцах диаметром $\sim 160$ мм
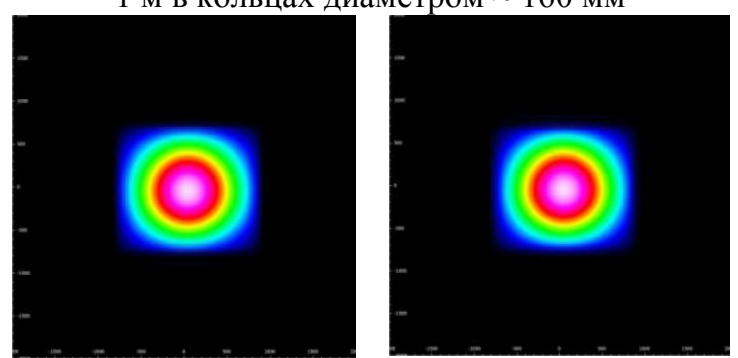

Рис. 6. Результаты измерения профиля лазерного пучка на выходе МС ОВ группы \#02 с периодом наведенной скрутки 66 оборотов/метр

Полученные результаты проведённой серии экспериментальных исследований пилотных образцов световодов демонстрируют принципиальную возможность практической реализации изготовления киральных МС ОВ с достаточно высоким периодом наведенной скрутки.

Исследование выполнено при финансовой поддержке РФФИ, DST, NSFC и NRF в рамках научного проекта № 19-57-80016 БРИКС_т 